\title{
The Shifts of Band Gap and Binding Energies of Titania/Hydroxyapatite Material
}

\author{
Nguyen Thi Truc Linh, ${ }^{1}$ Phan Dinh Tuan, ${ }^{2}$ and Nguyen Van Dzung ${ }^{3}$ \\ ${ }^{1}$ Ho Chi Minh City University of Pedagogy, Vietnam \\ ${ }^{2}$ Ho Chi Minh City University of Natural Resources and Environment, Vietnam \\ ${ }^{3}$ Institute of Applied Materials Science, VAST, Vietnam
}

Correspondence should be addressed to Nguyen Thi Truc Linh; nttlinh2811@gmail.com

Received 1 May 2014; Revised 22 June 2014; Accepted 23 June 2014; Published 10 July 2014

Academic Editor: Hui Shen Shen

Copyright (C) 2014 Nguyen Thi Truc Linh et al. This is an open access article distributed under the Creative Commons Attribution License, which permits unrestricted use, distribution, and reproduction in any medium, provided the original work is properly cited.

\begin{abstract}
The titania/hydroxyapatite $\left(\mathrm{TiO}_{2} / \mathrm{HAp}\right)$ product was prepared by precipitating hydroxyapatite in the presence of $\mathrm{TiO}(\mathrm{OH})_{2}$ gel in the hydrothermal system. The characteristics of the material were determined by using the measurements such as X-ray photoemission spectroscopy (XPS), X-ray diffraction (XRD), diffuse reflectance spectra (DRS), transmission electron microscopy (TEM), scanning electron microscopy (SEM), and energy dispersive X-ray (EDX). The XPS analysis showed that the binding energy values of $\mathrm{Ca}(2 \mathrm{p} 1 / 2,2 \mathrm{p} 3 / 2), \mathrm{P}(2 \mathrm{p} 1 / 2,2 \mathrm{p} 3 / 2)$, and $\mathrm{O} 1 \mathrm{~s}$ levels related to hydroxyapatite phase whereas those of Ti $(2 \mathrm{p} 3 / 2$,

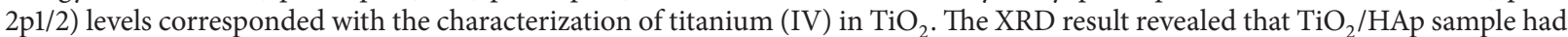
hydroxyapatite phase, but anatase or rutile phases were not found out. TEM image of $\mathrm{TiO}_{2} / \mathrm{HAp}$ product showed that the surface of the plate-shaped HAp particles had a lot of smaller particles which were considered as the compound of Ti. The experimental band gap of $\mathrm{TiO}_{2} / \mathrm{HAp}$ material calculated by the DRS measurement was $3.6 \mathrm{eV}$, while that of $\mathrm{HAp}_{\text {pure was }} 5.3 \mathrm{eV}$ and that of TiO pure was around $3.2 \mathrm{eV}$. The shift of the band gap energy of $\mathrm{TiO}_{2}$ in the range of 3.2-3.6 eV may be related to the shifts of Ti signals of XPS spectrum.
\end{abstract}

\section{Introduction}

$\mathrm{TiO}_{2}$ photocatalysis has gained much attention because of its low cost, nontoxicity, high stability, and easy preparation. However, the slow rates of the photocatalytic chemical transformations, compared with other methods, the low quantum yields, the lack of visible-light utilization, and the low adsorption capacity of $\mathrm{TiO}_{2}$ have hindered it from the practical application. To solve these problems, much effort has been made to enhance the photocatalytic efficiency and visible-light utilization of $\mathrm{TiO}_{2}$ by the additional components doping [1], improving its sensitization and metallization [2], or combining $\mathrm{TiO}_{2}$ and absorbable inorganic materials [3]. Recently, the preparation of titania/hydroxyapatite $\left(\mathrm{TiO}_{2} / \mathrm{HAp}\right)$ materials was attracting considerable attention thanks to the photocatalytic property of $\mathrm{TiO}_{2}$ and great adsorption ability of HAp. Among various features of the $\mathrm{TiO}_{2} / \mathrm{HAp}$ material which have been studied, the band gap evaluation was an important one because it decided the energy separation between the valence and conduction bands, the quantum effect, and the effect of visible-light utilization of that material [4]. The band gap of HAp was reported in [5] to be $3.95 \mathrm{eV}$ by photoluminescence measurement, meanwhile, in some papers, that of HAp was calculated to be around $4.51-5.4 \mathrm{eV}[6,7]$. The band gap of $\mathrm{TiO}_{2} / \mathrm{HAp}$ composites calculated by UV-Vis diffuse reflectance spectra was between 3.06 and $3.08 \mathrm{eV}$ while that of pure $\mathrm{TiO}_{2}$ was broader $(3.12 \mathrm{eV})$ [8]. However, the band gap of Tisubstituted hydroxyapatite evaluated by both experimental and theoretical methods was $3.65 \mathrm{eV}$ [9]. Generally, the above researches mainly focused on explaining the efficiency and photocatalytic mechanism of $\mathrm{TiO}_{2} / \mathrm{HAp}$ or Ti-substituted hydroxyapatite materials and have not mentioned the surface chemical bonding, particularly, the binding energy. In this study, the shifts of binding energy $\left(E_{B}\right)$ and band gap energy $\left(E_{g}\right)$ of $\mathrm{TiO}_{2} / \mathrm{HAp}$ material prepared by the hydrothermal process were investigated. 


\section{Experiment}

Calcium nitrate tetrahydrate, diammonium hydrogen phosphate, ammonia solution (pure analysis, Merck), and hydrous titania prepared from Ilmenite ore [10] were used as the original materials. The suspension of $\mathrm{TiO}(\mathrm{OH})_{2}$ gel in the aqueous solution of $\mathrm{Ca}\left(\mathrm{NO}_{3}\right)_{2} / \mathrm{EDTA}$ was added quickly into the aqueous solution of $\left(\mathrm{NH}_{4}\right)_{2} \mathrm{HPO}_{4}$ /urea and then stirred thoroughly. The mix was contained in the hydrothermal reactor adjusted to $180^{\circ} \mathrm{C}$ for 3 hours. The precipitate was filtered, washed, dried in vacuum at $65^{\circ} \mathrm{C}$ for $24 \mathrm{~h}$, and calcined up to $750^{\circ} \mathrm{C}$. The percentage of $\mathrm{TiO}_{2}$ in the $\mathrm{TiO}_{2} / \mathrm{HAp}$ product was below 10 (wt.\%).

The crystalline phases of the material were identified by powder X-ray diffraction (XRD) analyses using a ADVANCE A8-Bruker-Model 2006 diffractometer with $\mathrm{Cu}$ Ka radiation $(\lambda=0.15418 \mathrm{~nm})$. The element analysis was carried out by energy dispersive X-ray (EDX) spectroscopy (JSM-6610LA, $30 \mathrm{kV}$ ). The morphology, particle size, and size distribution of particles were investigated by JEM $1010(80 \mathrm{kV})$ transmission electron microscopy (TEM) and HITACHI S-4800 (5kV) scanning electron microscopy (SEM). X-ray photoemission spectroscopy measurement (XPS, Physical electronics, Model 04-548, USA) of the $\mathrm{TiO}_{2} / \mathrm{HAp}$ product was carried out at a pressure of higher than $1 \times 10^{-9}$ Torr. The general scan and the $\mathrm{C} 1 \mathrm{~s}, \mathrm{P} 2 \mathrm{p}, \mathrm{Ca} 2 \mathrm{p}, \mathrm{O} 1 \mathrm{~s}$, and Ti 2p core level spectra were recorded with unmonochromatized $\mathrm{Mg} \mathrm{K} \alpha$ radiation (photon energy $=1253.6 \mathrm{eV}$ ) at pass energy of $58.7 \mathrm{eV}$ and an electron take-off angle (angle between electron emission direction and surface plane) of $45^{\circ}$. The core level spectra were background corrected and the chemically distinct species were resolved using a nonlinear least squares fitting procedure in the Sun Solaris based Vision-2 curve resolver. The core level binding energies $\left(E_{B} s\right)$ were aligned with the adventitious carbon binding energy of $285 \mathrm{eV}$. The binding energy should be corrected by using the data of $\mathrm{C}$ 1s for the sample. The binding energy of the $\mathrm{TiO}_{2} / \mathrm{HAp}$ product was compared with those of $\mathrm{TiO}_{2}$ and HAp pure showed in MWI75, Handbook of XPS, page 240. The band gap $\left(E_{g}\right)$ values of $\mathrm{TiO}_{2}, \mathrm{HAp}$, and $\mathrm{TiO}_{2} / \mathrm{HAp}$ samples were evaluated by using UV-VIS diffuse reflectance spectra method (UV-VIS, JASCO V550).

\section{Results and Discussion}

The XRD pattern and EDX spectroscopy of $\mathrm{TiO}_{2} / \mathrm{HAp}$ sample was shown in Figure 1.

Figure 1(a) revealed that HAp, which is of the hexagonal structure and the molecular formula of $\mathrm{Ca}_{10}\left(\mathrm{PO}_{4}\right)_{6}(\mathrm{OH})_{2}$, had the characteristic peaks at the $2 \theta$ angles locations of $25.9,31.8,32.3,39.9$, and $49.5^{\circ}$ (JCPDS no. 00-009-0432). The characteristic peaks of $\mathrm{TiO}_{2}$ anatase did not appear in the XRD pattern of $\mathrm{TiO}_{2} / \mathrm{HAp}$ sample, even though $\mathrm{TiO}(\mathrm{OH})_{2}$ gel could be changed to $\mathrm{TiO}_{2}$ anatase after calcining up to $750^{\circ} \mathrm{C}[10]$. However, the EDX result showed that there were peaks of $\mathrm{Ca}, \mathrm{P}$, and $\mathrm{Ti}$ in the sample. That means either the percentage of $\mathrm{TiO}_{2}$ anatase in $\mathrm{TiO}_{2} / \mathrm{HAp}$ material was so small (below $10 \mathrm{wt} . \%$ ) or Ti was in a compound which could be not found out by the XRD result.

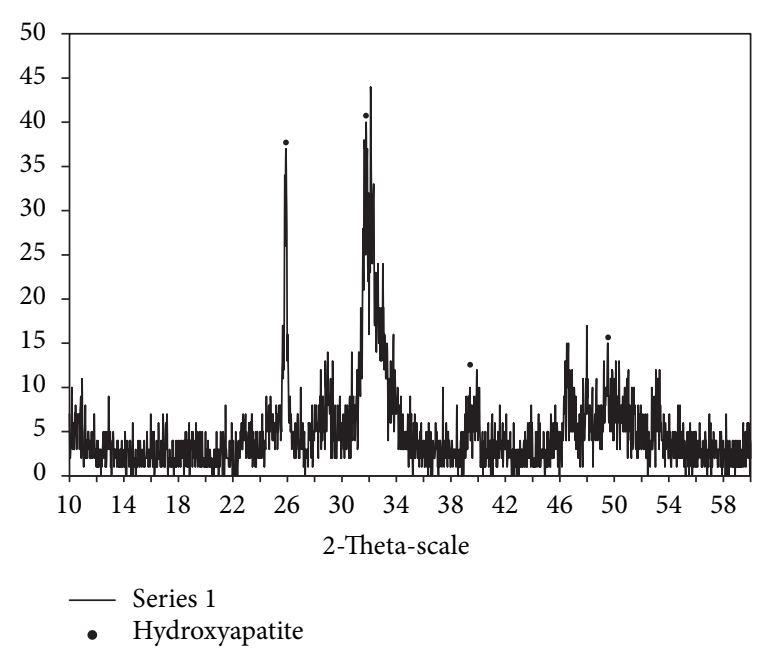

(a) XRD

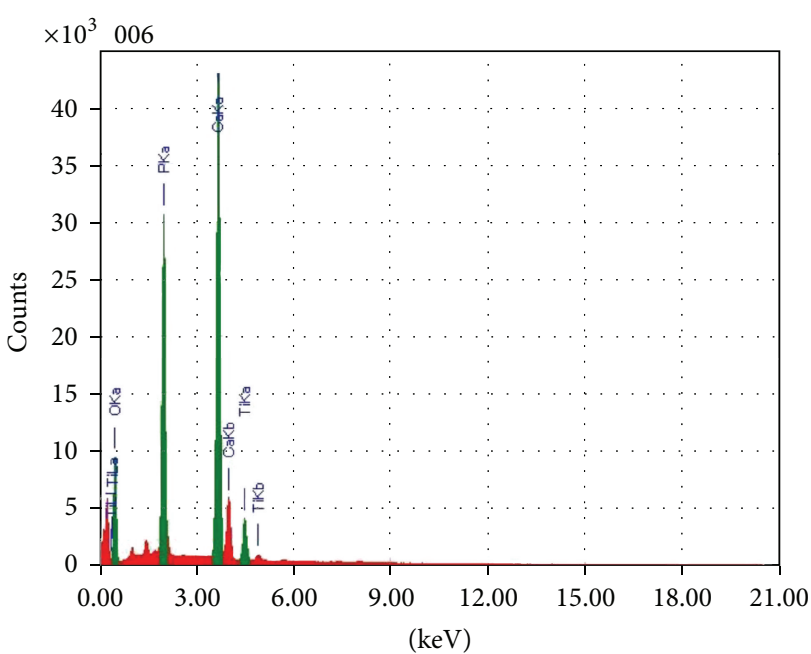

(b) EDX

FIGURE 1: XRD pattern and EDX spectroscopy of $\mathrm{TiO}_{2} / \mathrm{HAp}$ sample.

The SEM and TEM images of the sample were shown in Figure 2.

Figure 2(a) showed that $\mathrm{TiO}_{2} / \mathrm{HAp}$ material had plateshaped HAp particles at nanometer in thickness and at micrometer in the two remaining dimensions; meanwhile, Figure 2(b) indicated that the surface of HAp particles had a lot of smaller particles which were considered as the compound of Ti.

The XPS spectra of Ca 2p, O 1s, Ti 2p, and P 2p core levels of $\mathrm{TiO}_{2} / \mathrm{HAp}$ product were shown in Figure 3.

The figure of XPS result in the product exhibited a narrow scanning spectrum for analysis of chemical bonding. The binding energy of Ca 2p3/2 was $347.3 \mathrm{eV}$ and that of Ca $2 \mathrm{p} 1 / 2$ was 350.7 , which were related to hydroxyapatite. In case of the $\mathrm{O}$ 1s spectrum, the surface of the product was composed of three kinds of oxygen bonds which were $\mathrm{H}_{2} \mathrm{O}$ bond from hydrated surface, $\mathrm{PO}_{4}$ bond from hydroxyapatite, and oxide bond from titanium oxide $\left(\mathrm{TiO}_{2}\right)$. The binding energy of 


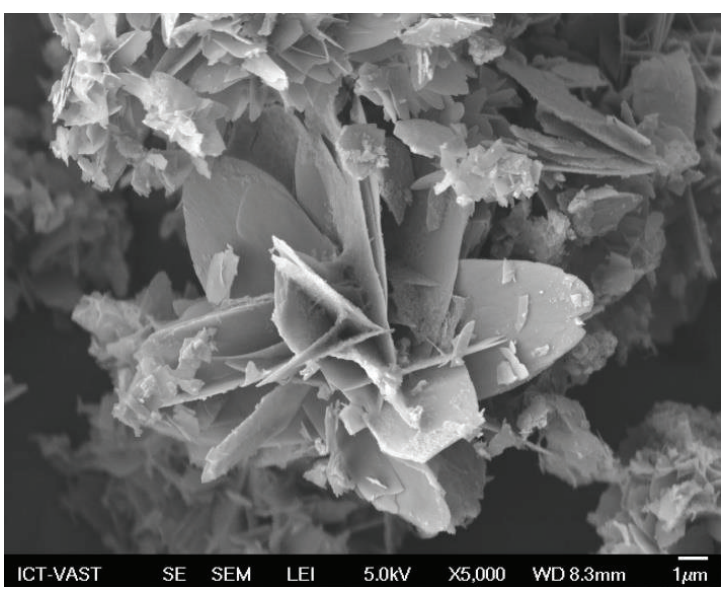

(a) SEM

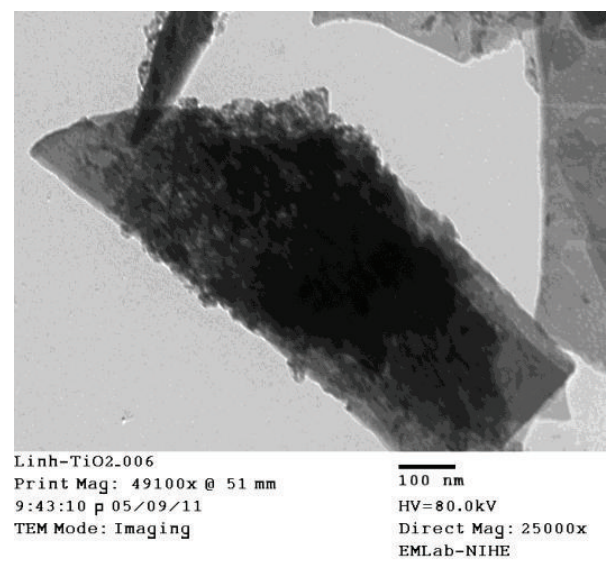

(b) TEM

FIgURE 2: SEM and TEM images of $\mathrm{TiO}_{2} / \mathrm{HAp}$ material.

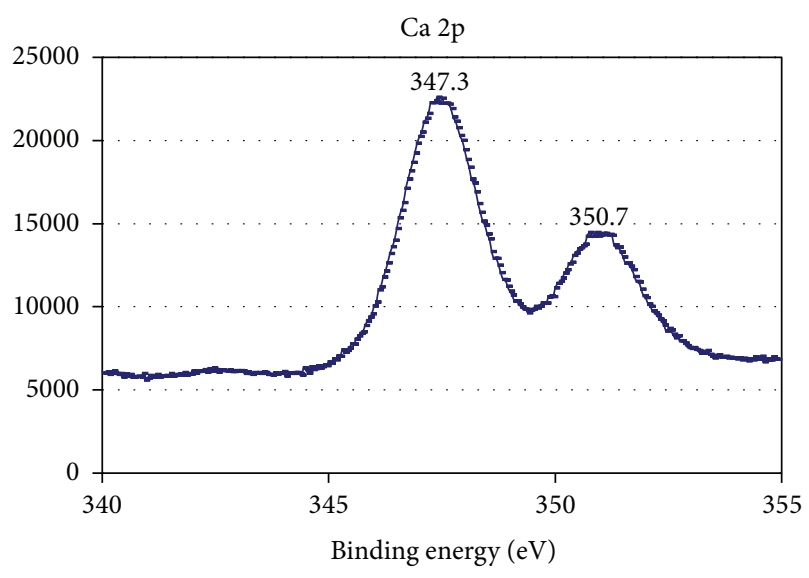

(a)

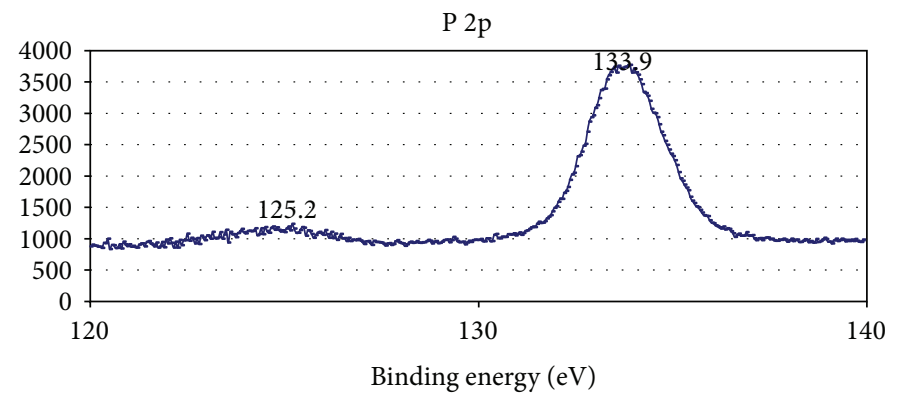

(c)

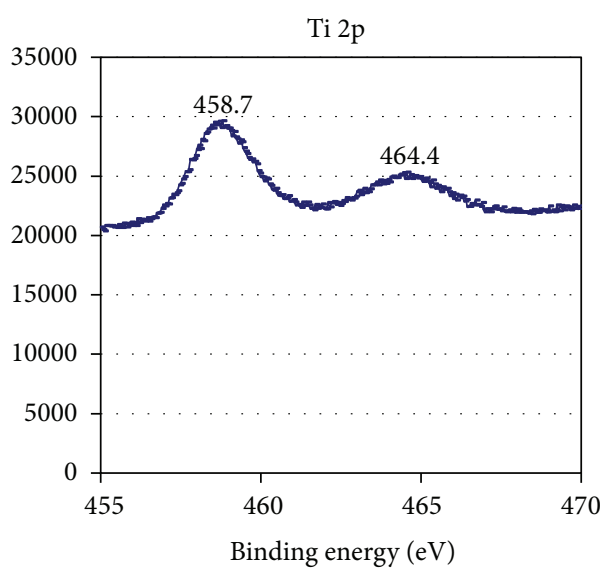

(b)

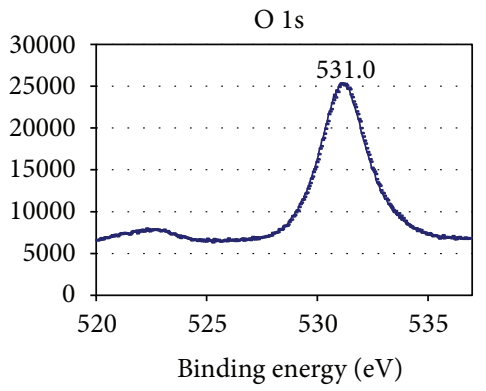

(d)

Figure 3: The XPS Ca 2p, O 1s, Ti 2p, and P 2p spectra of $\mathrm{TiO}_{2} / \mathrm{HAp}$ product.

$\mathrm{O}$ 1s attributed to the $\mathrm{PO}_{4}$ bond from hydroxyapatite was $531.4 \mathrm{eV}$. In case of the $\mathrm{P} 2 \mathrm{p}$ spectrum, the $\mathrm{P}$ peak was deconvoluted into two peaks for $\mathrm{p} 1 / 2$ and $\mathrm{p} 3 / 2$ levels with the binding energy of $133.9 \mathrm{eV}$, which corresponded with $\mathrm{P}$ in hydroxyapatite. The binding energy of $\mathrm{Ti} 2 \mathrm{p} 3 / 2$ in stoichiometric $\mathrm{TiO}_{2}$ has been reported to be in the range of 458.5 to $458.9 \mathrm{eV}$ and that of $\mathrm{Ti} 2 \mathrm{p} 3 / 2$ in $\mathrm{Ti}_{2} \mathrm{O}_{3}$ has been reported to be around 456.8 to $456.9 \mathrm{eV}$ [11]. The binding energy of $\mathrm{Ti} 2 \mathrm{p} 3 / 2$ in the product was $458.7 \mathrm{eV}$, so that of $\mathrm{Ti}$
$2 \mathrm{p} 3 / 2$ was much closer to that reported value for $\mathrm{TiO}_{2}$ than for $\mathrm{Ti}_{2} \mathrm{O}_{3}$.

However, according to the result of $\mathrm{Ti} 2 \mathrm{p}$ spectrum in pure $\mathrm{TiO}_{2}$, the binding energy of $\mathrm{Ti} 2 \mathrm{p} 3 / 2$ in $\mathrm{TiO}_{2}$ was $459.2 \mathrm{eV}$ (shown in Table 1) which corresponded with $\mathrm{Ti}$ in $\mathrm{TiO}_{2}$ anatase (MWI75, Handbook of XPS, page 240). In this case, the shift from $459.2 \mathrm{eV}$ to $458.7 \mathrm{eV}$ may be related to the atoms in different chemical states when $\mathrm{TiO}(\mathrm{OH})_{2}$ gel was converted to $\mathrm{TiO}_{2}$ in the material consisting of 


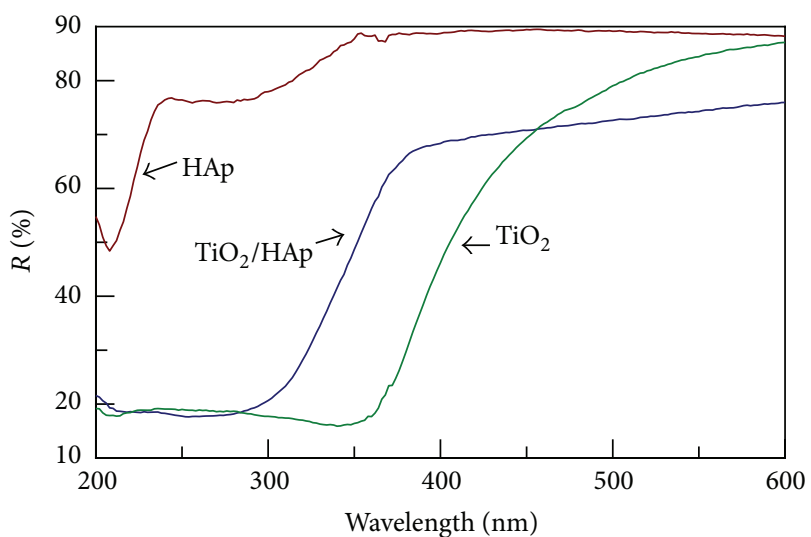

(a) DRS

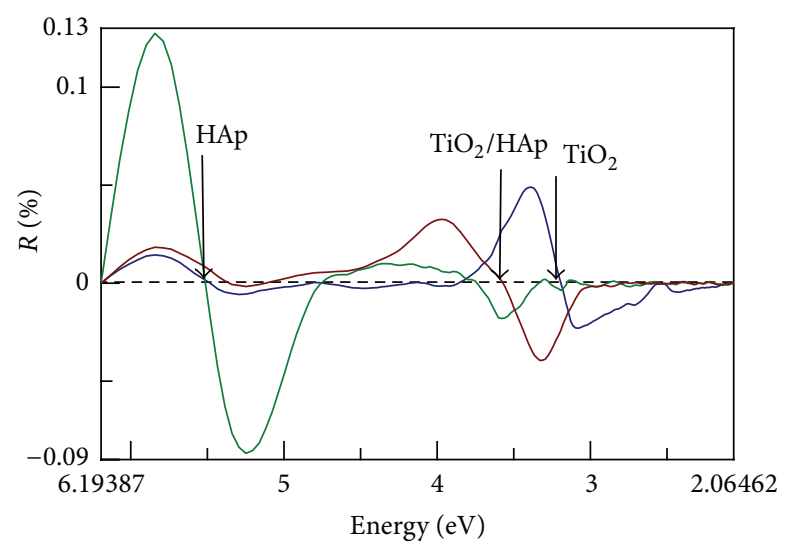

(b) 2nd order of derivatives (Algorithm Savitzky-Golay)

FIgURE 4: The diffuse reflectance spectra of $\mathrm{HAp}, \mathrm{TiO}_{2} / \mathrm{HAp}$, and anatase $\mathrm{TiO}_{2}$ powders.

TABLE 1: The band gap and the binding energy of the samples.

\begin{tabular}{lccc}
\hline \multirow{2}{*}{ Sample } & \multirow{2}{*}{ Band gap $(\mathrm{eV})$} & \multicolumn{2}{c}{ Binding energy (eV) } \\
& & $\mathrm{Ca} \mathrm{2p}$ & $\mathrm{Ti} 2 \mathrm{p}$ \\
\hline $\mathrm{TiO}_{2}$ anatase & 3.2 & - & 459.2 \\
$\mathrm{TiO}_{2} / \mathrm{HAp}$ & 3.6 & 347.3 & 458.7 \\
$\mathrm{HAp}$ & 5.3 & 347.3 & - \\
\hline
\end{tabular}

hydroxyapatite. In general, XPS binding energy shift was caused not only by chemical effects but also by matrix effects such as differences in crystal potential, work function, and relaxation energy [12].

The diffuse reflectance spectra of $\mathrm{HAp}, \mathrm{TiO}_{2} / \mathrm{HAp}$, and anatase $\mathrm{TiO}_{2}$ powders were shown in Figure 4.

The reflection edge wavelengths of $\mathrm{TiO}_{2} / \mathrm{HAp}$ and $\mathrm{TiO}_{2}$ were in the range of 340-400 $\mathrm{nm}$ whereas that of HAp was smaller than $250 \mathrm{~nm}$. In case of both $\mathrm{TiO}_{2}$ and $\mathrm{TiO}_{2} / \mathrm{HAp}$, the reflection in the VIS range was imperfect and there seemed to be small absorption in this range. The experimental band gap of $\mathrm{TiO}_{2} / \mathrm{HAp}$ product calculated by the DRS measurement was $3.6 \mathrm{eV}$, while that of HAp pure was $5.3 \mathrm{eV}$ and that of $\mathrm{TiO}_{2}$ pure was around $3.2 \mathrm{eV}$, which were listed in Table 1 . The measured $E_{g}$ of $\mathrm{TiO}_{2}$ of $3.2 \mathrm{eV}$ was the same as a generally known value of $3.2 \mathrm{eV}$ [13]. Additionally, $E_{g}$ of the pure HAp was $5.3 \mathrm{eV}$ which was in the range of $4.5-5.4 \mathrm{eV}$ reported in the previous studies [7]. However, the experimental $E_{g}$ of $\mathrm{TiO}_{2} / \mathrm{HAp}$ product was $3.6 \mathrm{eV}$ which was larger than that of $\mathrm{TiO}_{2}$ anatase, rutile, or brookite $[9,14]$. As a result, the analyses indicated that the main phase of the $\mathrm{TiO}_{2} / \mathrm{HAp}$ product was hydroxyapatite and the secondary phase was amorphous $\mathrm{TiO}_{2}$ or Ti-substituted hydroxyapatite. Moreover, it may have had a correlation between the shift of binding energy and the shift of band gap energy of the material.

\section{Conclusions}

$\mathrm{TiO}_{2} / \mathrm{HAp}$ material was successfully synthesized by precipitating hydroxyapatite in the presence of $\mathrm{TiO}(\mathrm{OH})_{2}$ gel in the hydrothermal system. XRD result revealed that $\mathrm{TiO}_{2} / \mathrm{HAp}$ sample had hydroxyapatite phase, but there was no anatase or rutile phase, even though $\mathrm{TiO}(\mathrm{OH})_{2}$ gel could be changed to $\mathrm{TiO}_{2}$ anatase after calcining up to $750^{\circ} \mathrm{C}$. TEM image of $\mathrm{TiO}_{2} / \mathrm{HAp}$ product showed that the surface of the plateshaped HAp particles had a lot of smaller particles which were considered as the compound of Ti. The binding energy values of $\mathrm{Ca} 2 \mathrm{p}, \mathrm{P} 2 \mathrm{p}$, and $\mathrm{O}$ 1s levels related to hydroxyapatite phase whereas those of $\mathrm{Ti} 2 \mathrm{p}$ levels corresponded with the characterization of titanium (IV) in $\mathrm{TiO}_{2}$. The shifts of binding energy and band gap energy of $\mathrm{TiO}_{2} / \mathrm{HAp}$ product compared to those of $\mathrm{TiO}_{2}$ anatase were $0.5 \mathrm{eV}$ and $0.4 \mathrm{eV}$, respectively. The shifts which may be related to the atoms in different chemical states when $\mathrm{TiO}(\mathrm{OH})_{2}$ gel was converted to $\mathrm{TiO}_{2}$ in the material consisting of hydroxyapatite should be continuosly studied in next works.

\section{Conflict of Interests}

The authors declare that there is no conflict of interests regarding the publication of this paper.

\section{References}

[1] M. A. Barakat, H. Schaeffer, G. Hayes, and S. Ismat-Shah, "Photocatalytic degradation of 2-chlorophenol by Co-doped $\mathrm{TiO}_{2}$ nanoparticles," Applied Catalysis B: Environmental, vol. 57, no. 1, pp. 23-30, 2005.

[2] Y. Xie and C. Yuan, "Visible-light responsive cerium ion modified titania sol and nanocrystallites for X-3B dye photodegradation," Applied Catalysis B: Environmental, vol. 46, no. 2, pp. 251-259, 2003.

[3] A. Nakajima, K. Takakuwa, Y. Kameshima et al., "Preparation and properties of titania-apatite hybrid films," Journal of Photochemistry and Photobiology A: Chemistry, vol. 177, no. 1, pp. 94-99, 2006.

[4] A. Fujishima and K. Honda, "Electrochemical photolysis of water at a semiconductor electrode," Nature, vol. 238, no. 5358, pp. 37-38, 1972.

[5] G. Rosenman, D. Aronov, L. Oster et al., "Photoluminescence and surface photovoltage spectroscopy studies of hydroxyapatite nano-Bio-ceramics," Journal of Luminescence, vol. 122-123, no. 1-2, pp. 936-938, 2007. 
[6] P. Rulis, L. Ouyang, and W. Y. Ching, "Electronic structure and bonding in calcium apatite crystals: hydroxyapatite, fluorapatite, chlorapatite, and bromapatite," Physical Review BCondensed Matter and Materials Physics, vol. 70, no. 15, Article ID 155104, 2004.

[7] K. Matsunaga and A. Kuwabara, "First-principles study of vacancy formation in hydroxyapatite," Physical Review B, vol. 75, Article ID 014102, pp. 1-9, 2007.

[8] A. Mitsionis, T. Vaimakis, C. Trapalis, N. Todorova, D. Bahnemann, and R. Dillert, "Hydroxyapatite/titanium dioxide nanocomposites for controlled photocatalytic NO oxidation," Applied Catalysis B: Environmental, vol. 106, no. 3-4, pp. 398404, 2011.

[9] M. Tsukada, M. Wakamura, N. Yoshida, and T. Watanabe, "Band gap and photocatalytic properties of Ti-substituted hydroxyapatite: comparison with anatase- $\mathrm{TiO}_{2}$," Journal of Molecular Catalysis A: Chemical, vol. 338, no. 1-2, pp. 18-23, 2011.

[10] N. T. T. Linh et al., in Proceedings of the 2nd International Conference on Natural Resources and Materials (ICNRM) and 4th AUN/SEED-Net Regional Conference on Natural Resources and Minerals (RCNRM '11), 2011.

[11] D. Gonbeau, C. Guimon, G. Pfister-Guillouzo, A. Levasseur, G. Meunier, and R. Dormoy, "XPS study of thin films of titanium oxysulfides," Surface Science, vol. 254, no. 1-3, pp. 81-89, 1991.

[12] K. S. Kim and N. Winograd, "X-ray photoelectron spectroscopic binding energy shifts due to matrix in alloys and small supported metal particles," Chemical Physics Letters, vol. 30, no. 1, pp. 91-95, 1975.

[13] L. Kavan, M. Grätzel, S. E. Gilbert, C. Klemenz, and H. J. Scheel, "Electrochemical and photoelectrochemical investigation of single-crystal anatase," Journal of the American Chemical Society, vol. 118, no. 28, pp. 6716-6723, 1996.

[14] A. Di Paola, M. Bellardita, and L. Palmisano, "Brookite, the least known $\mathrm{TiO}_{2}$ photocatalyst," Catalysts, vol. 3, no. 1, pp. 36-73, 2013. 

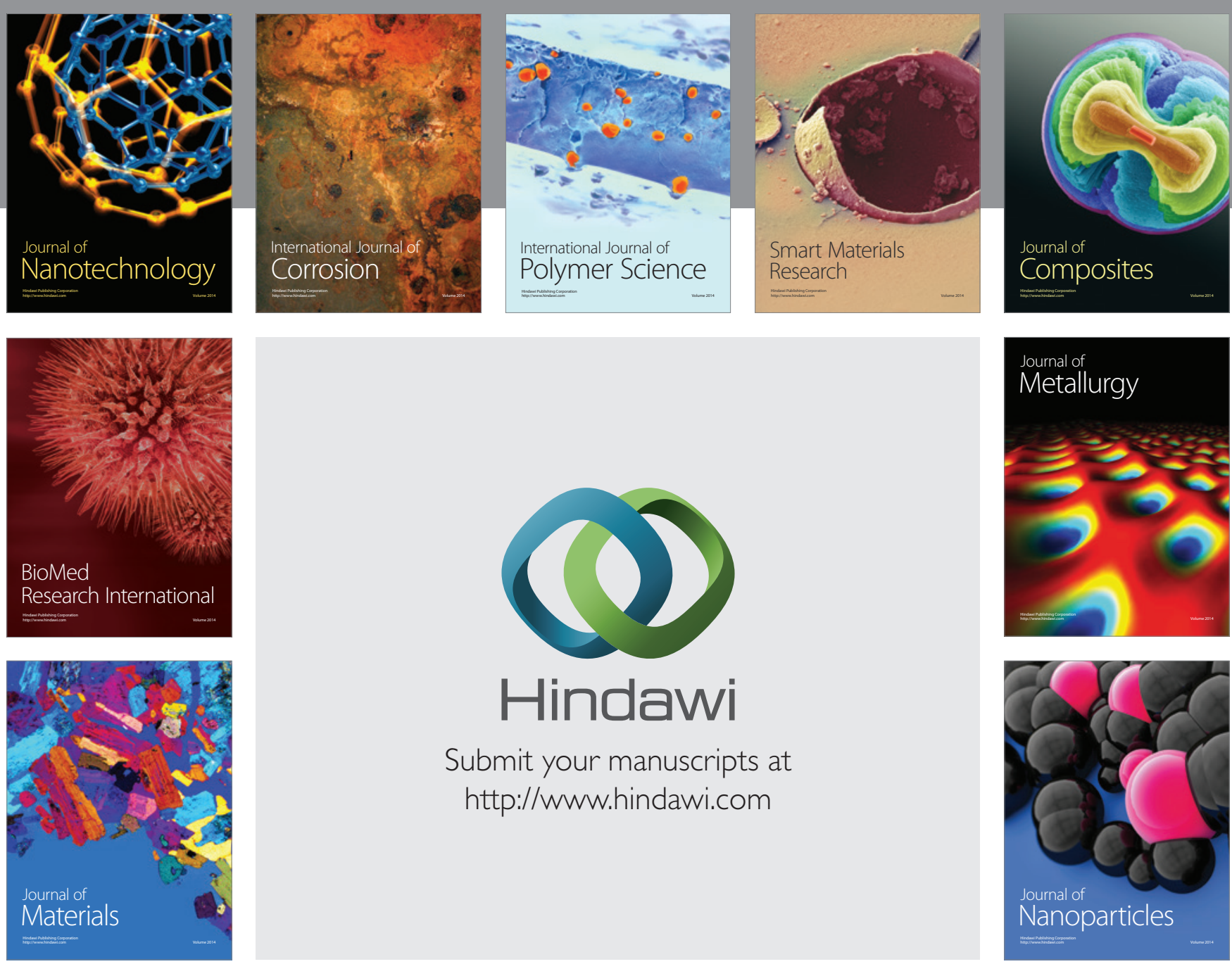

Submit your manuscripts at http://www.hindawi.com
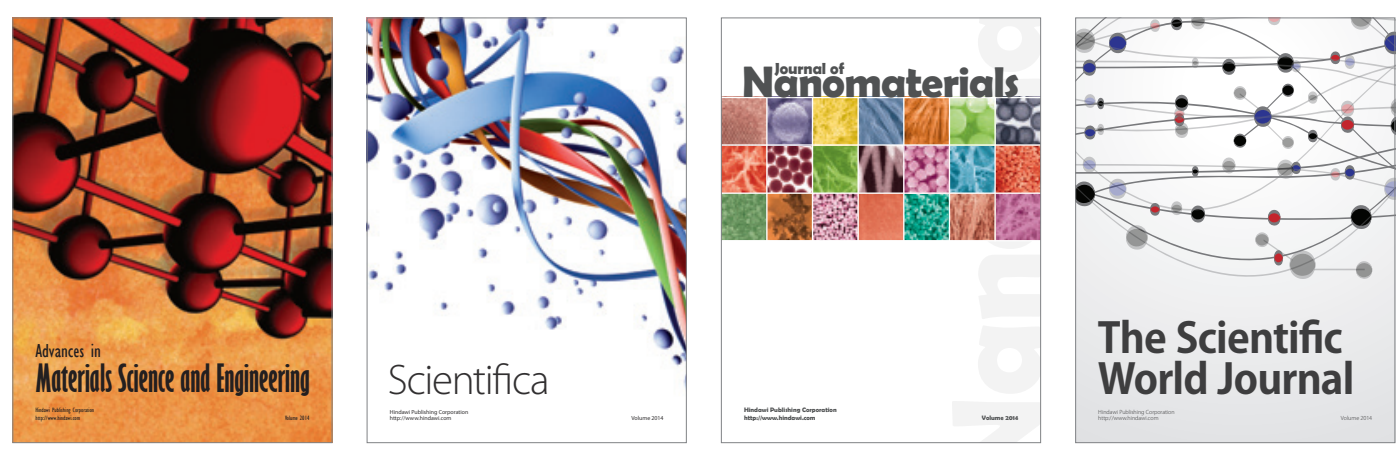

\section{The Scientific World Journal}
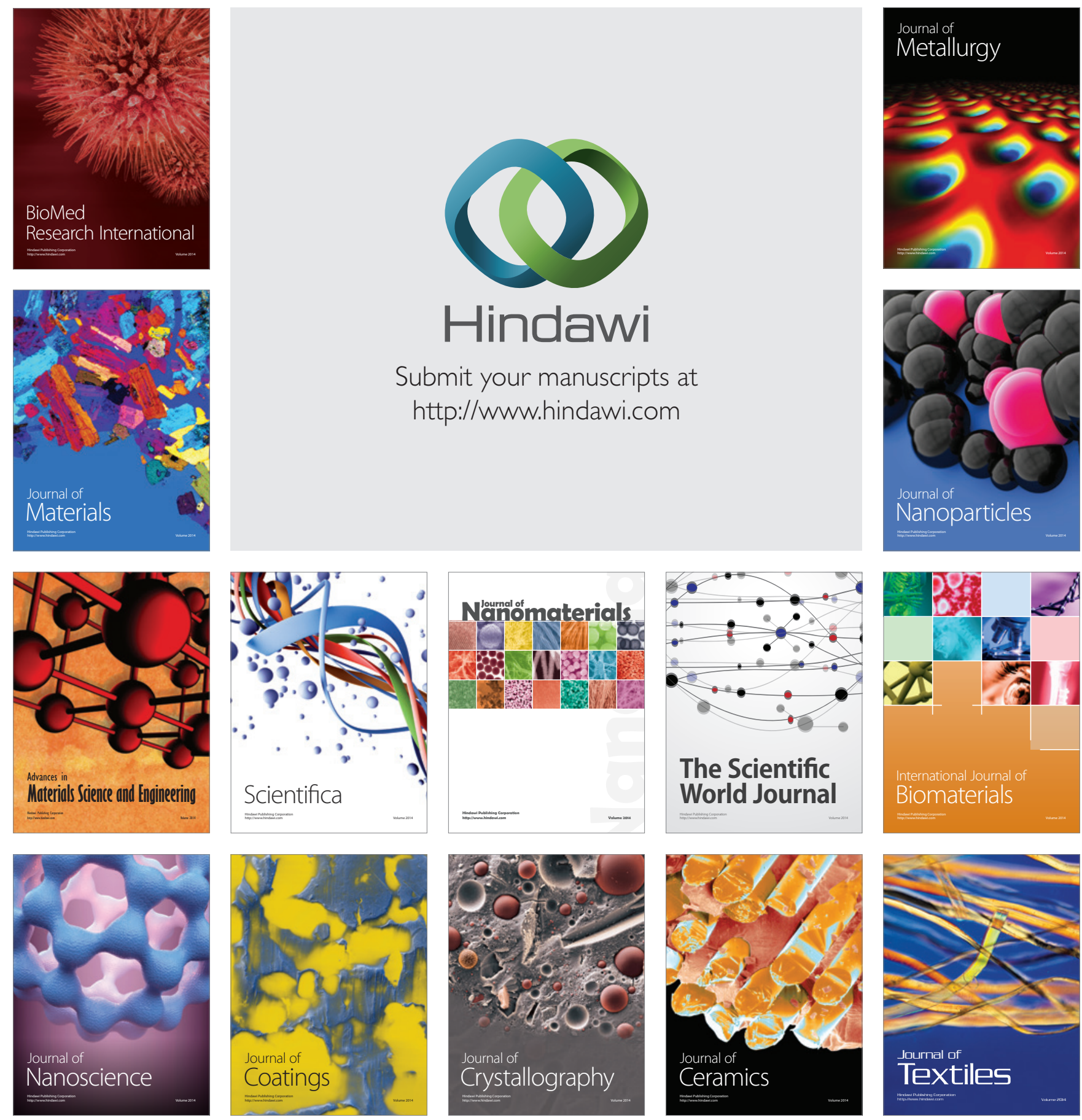